\title{
Cost-effectiveness analysis of interventions to achieve universal health coverage for schizophrenia in Mexico
}

\author{
Héctor Cabello-Rangel, ' Lina Díaz-Castro, ${ }^{2}$ Carlos Pineda-Antúnez ${ }^{3}$
}

Hospital Psiquiátrico Fray Bernardino Álvarez, Ciudad de México, México.

2 Dirección de Investigaciones Epidemiológicas y Psicosociales, Instituto Nacional de Psiquiatría Ramón de la Fuente Muñíz, Ciudad de México, México.

3 Departamento de Investigación de Servicios de Salud, Instituto Nacional de Salud Pública, Cuernavaca Morelos, México.

\section{Correspondence:}

Héctor Cabello Rangel

Hospital Psiquiátrico "Fray Bernardino Álvarez".

Av. San Buenaventura 2,

Col. Niño Jesús,

Tlalpan, 14000 Ciudad de México, México.

Phone: (+52 1) $555573-1500$ Email: hector19.05.19.05@gmail. com

Received: 18 April, 2019 Accepted: 12 October 2019

Citation:

Cabello-Rangel, H., Díaz-Castro, L., \& Pineda-Antúnez, C. (2020) Cost-effectiveness analysis of interventions to achieve universal health coverage for schizophrenia in Mexico. Salud Mental, 43(2), 65-71.

DOI: $10.17711 /$ SM. $0185-3325.2020 .010$

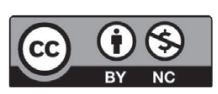

\begin{abstract}
Introduction. To achieve universal coverage in mental health, it is necessary to demonstrate which interventions should be adopted. Objective. Analyze the alternatives of pharmacological and psychosocial treatment in Mexico for patients diagnosed with schizophrenia, as well as Early Intervention in Psychosis Program. Method. The Extended cost effectiveness analysis (ECEA), it is implemented under scenario the option of treatment in Mexico, which includes: typical or atypical antipsychotic medication plus psychosocial treatment, assuming that all the medications will be provided to the patient, a measure of effectiveness is the years of life adjusted to disability (DALYs). Results. The effect of Universal Public Financing (UPF) is reflected in avoiding 147 DALYs for every 1,000,000 habitants. In addition, has a positive effect in the avoided pocket expenditures from US $\$ 101,221$ to US $\$ 787,498$ according to the type of intervention. Increasing government spending has a greater impact on the poorest quintile, as a distributive effect of the budget is generated. Respect to the value of insurance, the quintile III is the one who is most willing to pay for having insurance, on the other hand, in the highest income quintile, the minimum assurance valuation was observed. Discussion and conclusion. The reduction in out-of-pocket spending is uniform across all quintiles; "Early Intervention in Psychosis Program" is not viable for middle income countries, as México. The ECEA is a convenient method to assess the feasibility and affordability of mental health interventions to generate information for decision makers.
\end{abstract}

Keywords: Universal health coverage, schizophrenia, cost-effectiveness.

\section{RESUMEN}

Introducción. Para lograr la cobertura universal en salud mental es necesario demostrar qué intervenciones deberían ser adoptadas. Objetivo. Analizar las alternativas de tratamiento farmacológico y psicosocial para pacientes con esquizofrenia incluidas, así como un Programa de Intervención Temprana en Psicosis. Método. El análisis costo efectividad extendido (ECEA) se implementó bajo un escenario que incluye: medicación antipsicótica típica o atípica más tratamiento psicosocial, asumiendo que todos los medicamentos serán provistos a los pacientes, la medición de la efectividad en términos de DALYs. Resultados. El efecto del financiamiento público universal se refleja en evitar 147 DALYs por cada 1, 000,000 de habitantes. Además, tiene un efecto positivo en evitar pagos de bolsillo de US \$101,221 a US $\$ 787,478$ de acuerdo con el tipo de intervención. Incrementar el gasto del gobierno tiene un gran impacto sobre los quintiles más pobres como efecto distributivo del presupuesto. El quintil III de ingreso tiene mayor disposición a pagar el aseguramiento mientras que el quintil más rico tiene menor disposición a pagarlo. Discusión y conclusión. La reducción de los gastos de bolsillo es uniforme en todos los quintiles de ingreso, pero el "Programa de Intervención Temprana en Psicosis" no es viable generalizarlo para países de ingreso medio, como México. El ECEA es un método conveniente para evaluar la factibilidad y asequibilidad de intervenciones en salud mental para generar información para los tomadores de decisiones.

Palabras clave: Cobertura universal en salud, esquizofrenia, costo-efectividad. 


\section{INTRODUCTION}

Providing health services to the entire population and ensuring financial protection is one of the main objectives of a health system. The 2030 Sustainable Development Goals highlight the importance of protection against financial risks as part of a universal health coverage (Union Nations Organization, 2012). Mental disorders have an economic impact on the labor productivity of individuals, so that investing in them influences economic growth, hence the importance of evidencing which interventions must be adopted so that the health system manages to provide necessary services for the entire population. This means that interventions should be cost-effective, feasible, and affordable (World Health Organization, 2013).

In low and middle income countries, it is particularly difficult to decide which interventions should be included in the service packages in the absence of cost-effectiveness evidence. In this sense, interventions that include typical and/or atypical antipsychotic medication and psychosocial treatment are considered affordable, feasible, and effective (Patel, 2016; Chisholm \& Saxena, 2012). Applying these interventions would contribute to reducing the gap in mental health care, which in Latin America is currently from 58.0 to $44.4 \%$ (Kohn et al., 2005).

In Mexico, since 2003, the Social Protection System in Health (SPSS, initials for Sistema de Protección Social en Salud) in Spanish was established. Its main objective is to guarantee the financial protection of the population without social security. The SPSS provides health care services in the first and second levels of care through "Popular Insurance" (SP, initials of Seguro Popular). The health interventions for psychotic disorders (schizophrenia, delusions and schizotypal disorder) include a quarterly consultation, one to two annual hospitalizations, antipsychotic medication (risperidone, olanzapine, haloperidol, perphenazine, quetiapine, clozapine, levomepromazine, aripiprazole, trifluoperazine), and auxiliary diagnostic studies (laboratory and imaging) (Secretaría de Salud, 2005). Those interventions were integrated on the basis of recommendations from the WHO CHOICE project whose objective is to provide information on cost-effective interventions based on three key criteria: public health burden and importance; the availability of effective and potentially profitable interventions; and the availability of data on epidemiology, clinical effectiveness, use of resources and costs (Chisholm, 2005).

The cost-effectiveness analysis is an adequate economic evaluation method to provide relevant information to decide which interventions should be adopted. In Mexico there have been few cost-effectiveness studies of the interventions for the treatment of schizophrenia. For example, the evaluation of the effectiveness of different care strategies reported that psychosocial intervention without medication is less cost-effective than a comprehensive care strategy (psycho- social treatment + antipsychotic medication + psychoeducational treatment) and even interventions in which the hospital provided antipsychotic medication (Cabello-Rangel, Díaz-Castro, \& Arredondo, 2011). Another study considered the effectiveness as DALYS avoided based on a hypothetical coverage of $80 \%$ the cost of DALY avoided was $\$ 1,135,516$. 00 Mexican pesos, with antipsychotic treatment only, when adding psychosocial treatment, the cost is $\$ 390,892.00$ Mexican pesos (Lara-Muñoz et al., 2010).

The extended cost effectiveness analysis (ECEA) approach stems from the idea of providing protection against financial risks and consequently distribution of health benefits in population subgroups (quintiles), that is, it assesses the cost-effectiveness effect of a Universal Public Finance (UPF). It is a method that incorporates financial protection measures within economic evaluations of health policies. Its fundamental premises is that the UPF reduces the private expense and may influence the equalization between income groups for both financial and health outcomes (Verguet, Laxminarayan, \& Jamison, 2015).

The objective of this work is to perform an extended cost-effectiveness analysis and pharmacological and psychosocial treatment interventions afore mentioned for patients diagnosed with schizophrenia, as well as "Early Intervention in Psychosis Program" (EIP).

The EIP is a novel program of psychiatric hospital to treat first episode of psychosis with the aim of reducing medical and social complications as well as the comorbidities which flourish as a long-term result of the first episode of psychosis, through efficient treatment, focused on the patient and the family, the intervention of social workers, clinical psychologists, psychiatry and specialized nurses is necessary. Similar programs have been established and evaluated in other countries (McCrone, Knapp, \& Dhanasiri, 2009). Therefore, it is of interest to evaluate them considering the available resources of an economic middle-income country.

\section{METHOD}

An extended cost-effectiveness analysis study (ECEA) was designed in which the variable and fixed costs of outpatient care for schizophrenia interventions were analyzed and quantified. This is an atypical or typical antipsychotic medication and psychosocial treatment; in this model all medications will be provided to the patient.

\section{Interventions}

1. Intervention 1 (T1): Typical or atypical antipsychotic with same effectiveness (haloperidol $5 \mathrm{mg}$ and/or risperidone $2 \mathrm{mg}$ ) + biperiden $2 \mathrm{mg}$ + basic psychosocial treatment (outpatient). 
2. Intervention 2 (T2): Atypical antipsychotic (olanzapine $10 \mathrm{mg}$ ) + basic psychosocial treatment (outpatient).

3. Intervention 3 (T3): Atypical antipsychotic (olanzapine 10mg) + Early Intervention in Psychosis Program that includes: 1. intensive stage: management of the prodromal stage, acute and recovery of psychotic syndrome that includes psychiatric, and psychotherapeutic treatment for the patient and the family for nine months. 2. follow-up stage: scheduled appointments on a regular basis, but with a longer time interval, to monitor the established treatment.

\section{Variables}

Following the method developed by Verguet, the ECEA is based on a hypothetical population of one million inhabitants distributed in quintiles of 200,000 people, in which parameters that are assumed, and others used in previously published studies are applied, the risk aversion coefficient was estimated at 3\% (Verguet et al., 2015). According to the Institute for Health Metrics, the weight of disability for chronic cases is .576 and for acute cases .756, and the estimated prevalence for schizophrenia in Mexico is .22\%, according to the latest reports (Institute for Health Metrics, 2010).

The effectiveness of antipsychotic and psychosocial treatments is $46 \%$ and $49 \%$ for haloperidol and/or risperidone and olanzapine, respectively, at an equivalent dose of $15 \mathrm{mg} /$ day of haloperidol (olanzapine $20 \mathrm{mg} /$ day or risperidone $4 \mathrm{mg} /$ day) (Leucht, Pitschel-Walz, Abraham, \& Kissling, 1999). Adherence to treatment is $76 \%$ for all interventions (Chatterjee et al., 2014; Thieda, Beard, Richter, \& Kane, 2003). Early intervention in psychosis has a therapeutic adherence of 53\% (Solmi et al., 2018).

The percentage of current coverage of care by quintile and the Gross National Income per capita (GNI) is
US $\$ 815.61$; the participation in the GNI by income of quintile is $5.4 \%$ on the lowest and $52.2 \%$ on the highest, which represents that the lowest quintile of the population has a weighted income of US $\$ 398.90$ and the highest quintile of US $\$ 3859.08$, for the year 2014, so that a population of one million inhabitants would have an income of US $\$ 851,660,000.00$ and was based on that reported for Mexico by the World Bank (World Bank, 2018) (Table 1).

We consider that the population with Social Security has access to medicines and psychosocial care in the first and second level of medical care, which is concordant with the prevalence of coverage for low incidence mental disorders (Whiteford et al., 2013). For the present study, it is considered that in the highest income quintiles the prevalence is higher, given that they have better access and use of health care services, so that the probability of seeking care results from the product of the prevalence and the percentage of coverage in each quintile. The out-of-pocket expenditure for care medical is $66 \%$ of the monthly income (Wirtz, Santa-Ana-Tellez, Servan-Mori, \& Avila-Burgos, 2012).

\section{Treatment costs}

It includes variable and fixed costs; the variable costs (food, laundry, laboratory, water, electric power, municipal waste, cleaning, private security) derived from the current expenses incurred for the operation of the service were determined by the Primary Cost system. The fixed costs derived from human resources (medical, nursing, social work, psychology, and intendancy) were obtained from the coefficient of the annual gross salary between the annual workday in minutes for the time allocated to the care of each patient, both cost were published in a previous study (Cabello-Rangel et al., 2011).

Table 1

Variables for model Extend Cost-Effectiveness Analysis (ECEA)

\begin{tabular}{|c|c|c|c|c|c|c|}
\hline Inputs & & & Value & & & Reference \\
\hline \multicolumn{7}{|l|}{ Demography inputs } \\
\hline \multirow[t]{2}{*}{ Cohort size } & & & 1000000 & & & \\
\hline & I & II & III & IV & V & \\
\hline Cohort size per quintile & 200000 & 200000 & 200000 & 200000 & 200000 & \\
\hline Current coverage with social insurance & .16 & .344 & .636 & .716 & .492 & 17 \\
\hline Target coverage & .8 & .8 & .8 & .8 & .8 & \\
\hline Prevalence rate per quintile & .22 & .23 & .25 & .26 & .27 & 12 \\
\hline Overall probability of seeking care & .0352 & .07912 & .159 & 0.18616 & 0.13284 & $\begin{array}{l}\text { Prevalence } * \text { Current coverage } \\
\text { with social insurance }\end{array}$ \\
\hline Income inputs & & & $\$ 851.66$ & & & 17 \\
\hline$\%$ of participation of income per quintile & 5.4 & 9.4 & 13.4 & 19.6 & 52.2 & 17 \\
\hline Average monthly GDP per capita (US \$ at 2014) & 398.9 & 694.93 & 990.64 & 1449 & 3859.08 & 17 \\
\hline Average out-pocket expenditures. & & & $66 \%$ & & & 19 \\
\hline
\end{tabular}

Note: Project: Cabello-Rangel H, Diaz-Castro L, Pineda-Antúnez C. Extended cost-effective interventions for schizophrenia to achieve universal health coverage in Mexico.

Source: Authors. 
Table 2

Cost of interventions to treatment schizophrenia

\begin{tabular}{|c|c|c|c|c|}
\hline & Percent of cases & $\begin{array}{l}\text { Average annual } \\
\text { of out care } \\
\text { consultations }\end{array}$ & $\begin{array}{c}\text { Unitary Cost US } \$ \\
\text { (June 2018) }\end{array}$ & $\begin{array}{c}\text { Cost per case US } \$ \\
\text { (June 2018) }\end{array}$ \\
\hline $\begin{array}{l}\text { T1 = Psychosocial treatment }+ \text { typic or atypical antipsychotic } \\
\text { (Haloperidol/risperidone) }\end{array}$ & $100 \%$ & 4 & $\$ 1.78$ & $\$ 7.12$ \\
\hline $\begin{array}{l}\mathrm{T} 2=\text { Psychosocial treatment }+ \text { atypical antipsychotic (Olan- } \\
\text { zapine) }\end{array}$ & $100 \%$ & 4 & $\$ 1.78$ & $\$ 7.12$ \\
\hline $\begin{array}{l}\text { T3 = Early Intervention in Psychosis + atypical antipsychotic } \\
\text { (Olanzapine) }\end{array}$ & $80 \%$ & 15 & $\$ 35.70$ & $\$ 535.48$ \\
\hline \multicolumn{5}{|l|}{ Antipsychotics } \\
\hline Haloperidol 5mg (1) & $40 \%$ & 1095 & $\$ 0.07$ & $\$ 29.88$ \\
\hline Risperidone 2mg (2) & $30 \%$ & 2190 & $\$ 0.02$ & $\$ 13.80$ \\
\hline Olanzapine 10mg (3) & $20 \%$ & 730 & $\$ 1.75$ & $\$ 60.35$ \\
\hline Biperiden 2mg (T1) & $40 \%$ & 365 & $\$ 0.04$ & $\$ 13.09$ \\
\hline Laboratory test & $100 \%$ & 1 & & $\$ 14.04$ \\
\hline Total, T1 & & & & $\$ 77.93$ \\
\hline Total, T2 & & & & $\$ 81.51$ \\
\hline Total, T3 & & & & $\$ 606.29$ \\
\hline
\end{tabular}

Note: Project: Cabello-Rangel H, Diaz-Castro L, Pineda-Antúnez C. Extended cost-effective interventions for schizophrenia to achieve universal health coverage in Mexico.

Source: Authors.

The present value of these costs was calculated with compound interest:

$$
V F=V P(1+i)^{n}
$$

Where:

VF: Future value

VP: Present value

$i=$ Interes rate, (the rate that approximates the time preference of people, commonly used as $3 \%$ or $5 \%$ )

$n=$ Number of periods between present value and future value (Brigham \& Houston, 2005).

The cost of medications was based on current prices according to the purchase price of the IMSS International Public Bid for 2017 in Mexico (Instituto Mexicano del Seguro Social, 2017) (Table 2).

Disability Adjusted Life Years (DALYs) were used as the measure of effectiveness of the interventions, the DALYs were calculated with the method to determine the prevalence Years Lost by Disability, that is: YLD = prevalent cases * (size of the effect * adherence) * weight of disability * average duration of illness * target coverage (Raykar, Nigam, \& Chisholm, 2015).

Considering a population of one million people, a prevalence of 2200 cases of schizophrenia is estimated. It is assumed that $80 \%$ of the population would be covered with UPF, that is, 1760 cases.

Finally, the insurance value was calculated, which is the amount that an individual is willing to pay to receive health protection. For this, we estimated the expected value of the cost of treating schizophrenia without UPF at an individual level, using the following equation:

$$
Y p=(1-p) y+p(y-c)
$$

Where:

$p=$ probability of receiving attention for Schizophrenia.

$c=$ cost of treatment.

$y=$ income.

Following the estimation of the insurance value of Verguet et al. (2015), the following equation of certainty is considered:

$$
Y^{*}=\left[(1-p) y^{1-r}+p(y-c)^{1-r}\right]^{1 /(1-r)}
$$

Where $r$ is the coefficient of risk aversion (value $3 \%$ ).

At the individual level, the delta in the monetary value is:

$$
\operatorname{Delta}(v)=Y p-Y^{*}
$$

The insurance value at the population level by income quintile is:

$\operatorname{Delta}(v){ }^{*}$ Quintile size * Target coverage

\section{RESULTS}

Ensuring a coverage of $80 \%$ of the population has an impact of 98 and 106 DALYs are avoided in the poorest quintile for $\mathrm{T} 1$ and T2, respectively, and even in the richest quintiles it has a positive effect (Table 3 ).

In the current situation, the cost of intervention financed by the government to the population with social security is up to $80 \%$ higher for the quintiles with higher income compared to the poorest quintile. In the present analysis, the out-of-pocket expense for the cost of intervention and the prevalence of the disease by income quintile ranged from US \$ 60,930.00 to US \$474,035.43 (Table 4). 
Table 3

$D A L Y$ s evicted with interventions to treatment schizophrenia

\begin{tabular}{lrrrrrr}
\hline & \multicolumn{6}{c}{ Income quintile } \\
\cline { 2 - 7 } & \multicolumn{1}{c}{$I$} & \multicolumn{1}{c}{ III } & \multicolumn{1}{c}{ IV } & \multicolumn{1}{c}{ V } & Total \\
\hline DALY current burden & 465 & 515 & 611 & 1790 & 1153 & 4534 \\
T1 DALY evicted & 98 & 73 & 28 & 42 & 106 & 347 \\
T2 DALY evicted & 106 & 81 & 38 & 68 & 124 & 417 \\
T3 DALY evicted & 67 & 40 & 7 & 60 & 35 & 209 \\
\hline
\end{tabular}

Note: Project: Cabello-Rangel H, Diaz-Castro L, Pineda-Antúnez C. Extended cost-effective interventions for schizophrenia to achieve universal health coverage in Mexico.

Source: Authors.

The effect of ensuring coverage for $80 \%$ of the population through UPF avoids out-of-pocket expenses in direct proportion to the percentage of increase in coverage capacity, ensuring medication, and psychosocial treatment for patients with schizophrenia. It has a positive effect in the avoided pocket expense from US \$101,221 to US \$787,498 according to the type of intervention.

Increasing coverage generates an additional cost for the government that is not directly related to the reduction of DALYs by quintile, that is, increasing government spending has a greater impact on the poorest quintile since the cost-effectiveness ratio is higher in this one quintile given that the DALYS avoided are greater with very little difference compared to the quintiles of higher income, that is, a distributive effect of the budget is generated (Table 5).

The cost per capita of implementing each intervention, as the quantity of the total cost and the hypothetical population, is US $\$ 0.15$, US $\$ 0.16$ and US $\$ 1.19$ for T1, T2 and $\mathrm{T} 3$ respectively. This means that $\mathrm{T} 1$ and $\mathrm{T} 2$ are highly affordable and low cost, while option T3 is possibly affordable, according to the criteria to identify investment priorities in mental health (World Health Organization, 2013).

The value of the annual assurance at the population level is US \$ 7,627.14 for T2 and US \$ 6,958.86 for T1. This valuation is not homogeneous among the quintiles, since quintile III is the one which is most willing to pay for insurance with respect to the other quintiles. On the other hand, in the highest income quintile, the minimum assurance valuation was observed. In the case of T3, it was found that this option is highly expensive, with a monthly treatment cost seven times higher than the other two options (Table 2). In turn, T3 is not available for all the quintiles because the insurance cost exceeds the income. In fact, for quintile I the treatment cost is $50 \%$ higher than the income and for this reason, it was not possible to estimate the insurance value, since the term $(y-c)$ must be positive. Figure 1 shows the insurance value for the five quintiles of the two most cost-effective treatments.

\section{DISCUSSION AND CONCLUSION}

In terms of the global burden of the disease, in 2016 in Mexico mental disorders were the fourth cause within the category of disability-adjusted life years (DALYs). However, the organized social response has been inadequate. Most people suffering from mental disorders, such as schizophrenia, do not seek or receive care due to lack of services and/or stigma, reflecting the huge attention gaps observed: around $69 \%$ for people with severe mental disorders (such as schizophrenia) in low-middle income countries do not receive treatment (Lora et al., 2012).

In the specific case of universal health coverage for schizophrenia, it was necessary to know the prevalence and cost of care to plan health care service, prioritize available resources, and establish the cost-effectiveness of current and future interventions.

In Mexico, under current conditions, the distribution of the budget for the care of patients with schizophrenia is inequitable. It is up to five times higher in the richest quintile than in the poorest one. The research carried out shows the approach to reduce the existing inequity in the population suffering from schizophrenia, given the current modalities of care in the country.

Table 4

Cost of intervention to treatment schizophrenia with current coverage

\begin{tabular}{|c|c|c|c|c|c|c|c|c|}
\hline & & & I & II & III & IV & $V$ & Total \\
\hline \multirow{9}{*}{ 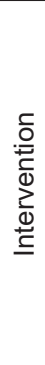 } & \multirow{3}{*}{ T1 } & Total cost of intervention & $\$ 5,486.27$ & $\$ 12,331.64$ & $\$ 24,781.74$ & $\$ 29,014.90$ & $\$ 20,704.44$ & $\$ 92,319.00$ \\
\hline & & Private expenditure & $\$ 3,620.94$ & $\$ 8,138.88$ & $\$ 16,355.95$ & $\$ 19,149.83$ & $\$ 13,664.93$ & $\$ 60,930.54$ \\
\hline & & Cost financial by government & $\$ 1,865.33$ & $\$ 4,192.76$ & $\$ 8,425.79$ & $\$ 9,865.07$ & $\$ 7,039.51$ & $\$ 31,388.46$ \\
\hline & \multirow{3}{*}{ T2 } & Total cost of intervention & $\$ 5,738.21$ & $\$ 12,897.92$ & $\$ 25,919.74$ & $\$ 30,347.28$ & $\$ 21,655.21$ & $\$ 96,558.35$ \\
\hline & & Private expenditure & $\$ 3,787.22$ & $\$ 8,512.63$ & $\$ 17,107.03$ & $\$ 20,029.21$ & $\$ 14,292.44$ & $\$ 63,728.51$ \\
\hline & & Cost financial by government & $\$ 1,950.99$ & $\$ 4,385.29$ & $\$ 8,812.71$ & $\$ 10,318.08$ & $\$ 7,362.77$ & $\$ 32,829.84$ \\
\hline & \multirow{3}{*}{ T3 } & Total cost of intervention & $\$ 42,682.86$ & $\$ 95,939.42$ & $\$ 192,800.40$ & $\$ 225,734.11$ & $\$ 161,079.28$ & $\$ 718,236.07$ \\
\hline & & Private expenditure & $\$ 28,170.69$ & $\$ 63,320.02$ & $\$ 127,248.27$ & $\$ 148,984.51$ & $\$ 106,312.33$ & $\$ 474,035.81$ \\
\hline & & Cost financial by government & $\$ 14,512.17$ & $\$ 32,619.40$ & $\$ 65,552.14$ & $\$ 76,749.60$ & $\$ 54,766.96$ & $\$ 244,200.26$ \\
\hline
\end{tabular}

Note: Project: Cabello-Rangel H, Diaz-Castro L, Pineda-Antúnez C. Extended cost-effective interventions for schizophrenia to achieve universal health coverage in Mexico.

Source: Authors. 
Table 5

Cost of intervention to treatment schizophrenia with coverage $80 \%$

\begin{tabular}{|c|c|c|c|c|c|c|c|c|}
\hline & & & I & II & III & IV & V & Total \\
\hline \multirow{15}{*}{ 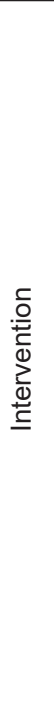 } & \multirow{5}{*}{ T1 } & Total de cost of intervention & $\$ 27,431.36$ & $\$ 28,678.24$ & $\$ 31,172.00$ & $\$ 32,418.88$ & $\$ 33,665.76$ & $\$ 153,366.24$ \\
\hline & & Additional cost for the government & $\$ 21,945.09$ & $\$ 16,346.60$ & $\$ 6,390.26$ & $\$ 3,403.98$ & $\$ 12,961.32$ & $\$ 61,047.24$ \\
\hline & & Out-of-pocket averted & $\$ 18,104.70$ & $\$ 18,927.64$ & $\$ 20,573.52$ & $\$ 21,396.46$ & $\$ 22,219.40$ & $\$ 101,221.72$ \\
\hline & & $\begin{array}{l}\text { Ratio cost-effectiveness (Cost/ } \\
\text { DALY averted) }\end{array}$ & $\$ 223.93$ & $\$ 223.93$ & $\$ 228.22$ & $\$ 81.05$ & $\$ 122.28$ & \\
\hline & & Value insurance & $\$ 1,336.50$ & $\$ 1,595.13$ & $\$ 2,030.88$ & $\$ 1,557.85$ & $\$ 438.49$ & $\$ 6,958.86$ \\
\hline & \multirow{5}{*}{$\mathrm{T} 2$} & Total de cost of intervention & $\$ 28,691.03$ & $\$ 29,995.17$ & $\$ 32,603.44$ & $\$ 33,907.58$ & $\$ 35,211.72$ & $\$ 160,408.94$ \\
\hline & & Additional cost for the government & $\$ 22,952.82$ & $\$ 17,097.25$ & $\$ 6,683.71$ & $\$ 3,560.30$ & $\$ 13,556.51$ & $\$ 63,850.58$ \\
\hline & & Out-of-pocket averted & $\$ 18,936.08$ & $\$ 19,796.81$ & $\$ 21,518.27$ & $\$ 22,379.00$ & $\$ 23,239.73$ & $\$ 105,869.90$ \\
\hline & & $\begin{array}{l}\text { Ratio cost-effectiveness (Cost/ } \\
\text { DALY averted) }\end{array}$ & $\$ 216.54$ & $\$ 211.08$ & $\$ 175.89$ & $\$ 52.36$ & $\$ 109.33$ & \\
\hline & & Value insurance & $\$ 1,467.51$ & $\$ 1,748.63$ & $\$ 2,225.09$ & $\$ 1,706.03$ & $\$ 479.88$ & $\$ 7,627.14$ \\
\hline & \multirow{5}{*}{ T3 } & Total de cost of intervention & $\$ 213,414.28$ & $\$ 223,114.93$ & $\$ 242,516.23$ & $\$ 252,216.88$ & $\$ 261,917.53$ & $\$ 1,193,179.86$ \\
\hline & & Additional cost for the government & $\$ 170,731.43$ & $\$ 127,175.51$ & $\$ 49,715.83$ & $\$ 26,482.77$ & $\$ 100,838.25$ & $\$ 474,943.79$ \\
\hline & & Out-of-pocket averted & $\$ 140,853.43$ & $\$ 147,255.86$ & $\$ 160,060.71$ & $\$ 166,463.14$ & $\$ 172,865.57$ & $\$ 787,498.71$ \\
\hline & & $\begin{array}{l}\text { Ratio cost-effectiveness (Cost/ } \\
\text { DALY averted) }\end{array}$ & $\$ 2,548.23$ & $\$ 3,179.39$ & $\$ 7,102.26$ & $\$ 441.38$ & $\$ 2,881.09$ & \\
\hline & & Value insurance & NA & $\$ 155,178.57$ & $\$ 162,797.95$ & $\$ 112,351.84$ & $\$ 28,069.55$ & $\$ 458,397.91$ \\
\hline
\end{tabular}

Notes: NA: This value was not estimated since the treatment cost was higher than income therefore the negative difference could not be used in the Value Insurance equation.

Project: Cabello-Rangel H, Diaz-Castro L, Pineda-Antúnez C. Extended cost-effective interventions for schizophrenia to achieve universal health coverage in Mexico.

Source: Authors.

Under the premise of establishing a UPF to ensure that the population with schizophrenia receives available and affordable treatment, our research showed that two basic interventions such as typical or atypical antipsychotic treatment with same effectiveness + psychosocial treatment (T1) or atypical antipsychotic treatment + psychosocial treatment (T2), have a positive effect on the distribution of health spending, as evidenced by the extended cost-effectiveness analysis in the DALYs avoided. This interventions

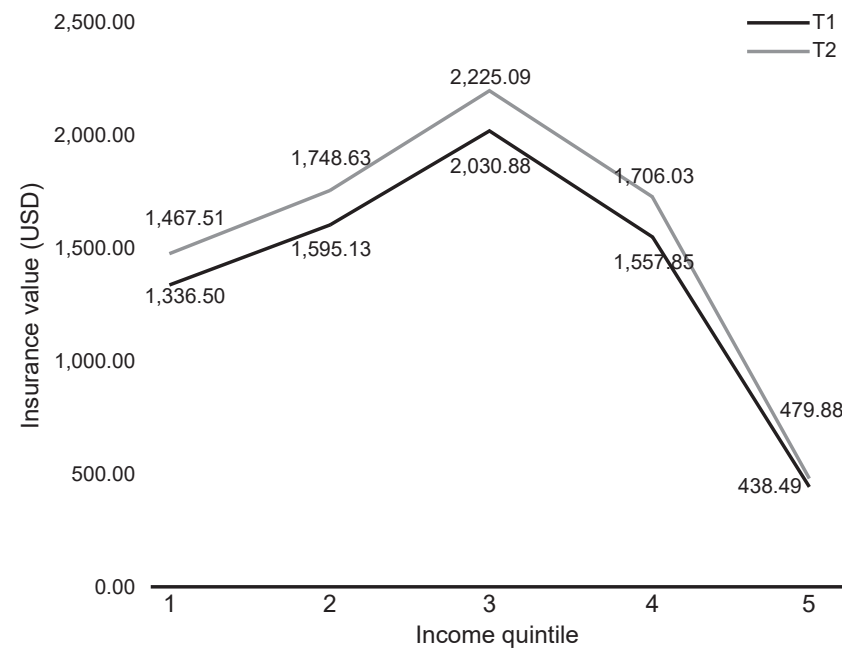

Figure 1. Insurance value per quintilie. would create a more equitable health system, by systematically incorporating the health care required and accessible to this population, which would impact on patient, family, and social costs. In our opinion, the results serve as a substrate for the planning of mental health services with an effect of distributive justice of wealth.

If it is analyzed from the point of view of the value of the assurance, that is, of the user's willingness to pay for interventions for $\mathrm{T} 1$ and $\mathrm{T} 2$, it is very similar, and is below the average level of income for each quintile, so they are very affordable.

Other currently available interventions, which require a higher degree of specialization and human resources per case, are not viable in middle-income countries such as Mexico. For instance, the EIP is not viable at population level, and the cost of treatment and willingness to pay is only feasible for the richest quintiles.

The extended cost-effectiveness analysis is essential before funding a health intervention to avoid incurring in the error of allocating budget to non-cost-effective interventions for the system. In the specific case of Mexico, it is necessary to reevaluate health interventions, particularly medicines. This in the understanding that the highest outof-pocket expenses incurred by users of services, and the one that generate catastrophic health expenditure, is in the purchase of medicines. In this sense, T2 proves to be a viable option to expand treatment coverage in schizophrenia, because it is a highly cost-effective strategy and the most 
efficient of the three treatments analyzed in the present work, in addition to showing a greater value of population insurance.

Finally, the ECEA is an accessible method to generate information that allows decision makers to incorporate or exclude therapeutic interventions to achieve universal health coverage, as demonstrated in the present investigation.

\section{Funding}

None.

\section{Conflicts of interest}

The authors declare they have no conflicts of interest.

\section{REFERENCES}

Brigham, E. F., \& Houston, J. F. (2005). Fundamentals of financial management (10th Edition). Ed Thomson.

Cabello-Rangel, H., Díaz-Castro, L., \& Arredondo, A. (2011). Costo-efectividad de intervenciones para esquizofrenia en México. Salud Mental, 34(2), 95-102.

Chatterjee, S., Naik, S., John, S., Dabholkar, H., Balaji, M., Koschorke, M., ... Thornicroft, G. (2014). Effectiveness of a community-based intervention for people with schizophrenia and their caregivers in India (COPSI): A randomized controlled trail. The Lancet, 383(9926), 1385-1394. doi: 10.1016/S01406736(13)62629-X

Chisholm, D. (2005). Choosing cost-effective interventions in psychiatry: Results from the CHOICE programme of the World Health Organization. World Psychiatry, 4(1), 37-44.

Chisholm, D., \& Saxena, S. (2012). Cost effectiveness of strategies to combat neuropsychiatric conditions in sub-Saharan Africa and South East Asia: mathematical modelling study. British Medical Journal, 344, e609. doi: 10.1136/bmj.e609

Institute for Health Metrics. (2010). Global Burned Diseases. Retrieved from https:// vizhub.healthdata.org/gbd-compare/

Instituto Mexicano del Seguro Social. (2017). Documentación compra consolidada 2016-2017. Retrieved from http://www.imss.gob.mx/compraconsolidada/2016

Kohn, R., Levav, I., Caldas de Almeida, J. M., Vicente, B., Silveira Guerra Andrade, L. H., Caraveo-Anduaga, J. J., Saxena, S., \& Saraceno, B. (2005). Mental disorders in Latin America and the Caribbean: a public health priority. Revista Panamericana de Salud Pública, 18(4-5), 229-240. doi: 10.1590/s102049892005000900002

Lara-Muñoz, M. C., Robles-García, R., Orozco, R., Saltijeral Méndez, M. T., Medina-Mora, M. E., \& Chisholm, D. (2010). Estudio de costo-efectividad del tratamiento de la esquizofrenia en México. Salud Mental, 33(3), 211-218.
Leucht, S., Pitschel-Walz, G., Abraham, D., \& Kissling, W. (1999). Efficacy and extrapyramidal side-effects of the new antipsychotics olanzapine, quetiapine, risperidone, and sertindole compared to conventional antipsychotics and placebo. A meta-analysis of randomized controlled trials. Schizophrenia Research, 35(1), 51-68. doi: 10.1016/s0920-9964(98)00105-4

Lora, A., Kohn, R., Levav, I., McBain, R., Morris, J., \& Saxena, S. (2012). Service availability and utilization and treatment gap for schizophrenic disorders: a survey in 50 low- and middle-income countries. Bulletin of the World Health Organization, 90, 47-54B. doi: 10.2471/BLT.11.089284

McCrone, P., Knapp, M., \& Dhanasiri, S. (2009). Economic impact of services for first-episode psychosis: A decision model approach. Early Intervention in Psychiatry, 3(4), 266-273. doi: 10.1111/j.1751-7893.2009.00145.x

Patel, V. (2016). Universal health coverage for schizophrenia: A global mental health priority. Schizophrenia Bulletin, 42(4), 885-890. doi: 10.1093/schbul/sbv107

Raykar, N., Nigam, A., \& Chisholm, D. (2015). An extended cost-effectiveness analysis of schizophrenia treatment in India under universal public finance. Cost Effectiveness and Resource Allocation, 14(1), 9. doi: 10.1186/s12962-0160058-z

Secretaria de Salud. (2005). Sistema de Protección Social en Salud. Elementos conceptuales, financieros y operativos. México, D. F. ISBN 970-721-290X. Retrieved from http://www.salud.gob.mx/unidades/cdi/documentos/ DOCSAL7723.pdf

Solmi, F., Mohammadi, A., Perez, J. A., Hameed, Y., Jones, P. B., \& Kirkbride, J. B. (2018). Predictors of disengagement from Early Intervention in Psychosis services. The British Journal of Psychiatry, 213(2), 477-483. doi: 10.1192/ bjp. 2018.91

Thieda, P., Beard, S., Richter, A., \& Kane, J. (2003). An economic review of compliance with medication therapy in treatment of schizophrenia. Psychiatric Services, 54(4), 508-516. doi: 10.1176/appi.ps.54.4.508

Union Nations Organization. (2012). Sustainable Development Goals 2030. Genève Switzerland.

Verguet, S., Laxminarayan, R., \& Jamison, D. T. (2015). Universal public finance of tuberculosis treatment in India: An extended cost-effectiveness analysis. Health Economics, 24(3), 318-332. doi: 10.1002/hec.3019

Whiteford, H. A., Degenhardt, L., Rehm, J., Baxter, A. J., Ferrari, A. J., Erskine, H. E., ... Vos, T. (2013). Global burden of disease attributable to mental and substance use disorders: findings from the Global Burden of Disease Study 2010. The Lancet, 382(9904), 1575-1586. doi: 10.1016/S0140-6736(13)61611-6

Wirtz, V. J., Santa-Ana-Tellez, Y., Servan-Mori, E., \& Avila-Burgos, L. (2012). Heterogeneous effects of health insurance on out-of-pocket expenditure on medicines in Mexico. Value in Health, 15(5), 593-603. doi: 10.1016/j. jval.2012.01.006

World Bank. (s.f.). Indicadores del desarrollo mundial [Conjunto de datos]. Access date: July 2018. Retrieved from https://databank.bancomundial.org/reports. aspx? source=world-development-indicators

World Health Organization (2013). Investing in mental health: evidence for action. Geneva, Switzerland. 